\title{
Microbial influences on the small intestinal response to radiation injury
}

\author{
Christopher D. Packey ${ }^{a}$ and Matthew A. Ciorba ${ }^{b}$ \\ aDivision of Gastroenterology, Department of Microbiology and Immunology, University of North \\ Carolina, Chapel Hill, North Carolina \\ bDivision of Gastroenterology, Washington University School of Medicine, Saint Louis, Missouri, \\ USA
}

\begin{abstract}
Purpose of review-Injury to the small bowel from ionizing radiation occurs commonly in patients undergoing cancer therapy and less commonly in instances of accidental radiation overexposure. Several lines of evidence now suggest that dynamic interactions between the host's enteric microbiota and innate immune system are important in modulating the intestinal response to radiation. Here, we will review recent developments in the area of acute radiation enteropathy and examine the current state of knowledge regarding the impact of host-microbial interactions in the process.
\end{abstract}

Recent findings-There is promise in the development and testing of new clinical biomarkers including serum citrulline. Toll-like receptor agonists and innate immune system signaling pathways including nuclear factor-kappa B profoundly alter intestinal epithelial cell apoptosis and crypt survival after radiation exposure. Germ-free conditions, probiotics and antibiotics are each identified as modifiers of disease development and course. A human study suggested that luminal microbiota composition may influence the host's intestinal response to radiation and may change in those developing postradiation diarrhea.

Summary-New knowledge implies that investigations aimed at deciphering the microbiomehost interactions before and after small bowl radiation injury may eventually allow prediction of disease course and offer opportunities for the development of novel therapeutic or prophylactic strategies.

\section{Keywords}

antibiotic; innate immune; microbiome; probiotic; radiation enteritis; radiation enteropathy

\section{Introduction}

The mammalian microbiome, as it relates to health and disease, has received increasing attention in medical research over the last decade. The human body is inhabited by at least 
10 times more bacteria than the number of somatic and germline cells. The National Institutes of Health has funded the Human Microbiome Project (HMP) as a roadmap initiative to characterize the human microbiome in five body sites from healthy volunteers, including the gastrointestinal tract [1•]. Perhaps not coincidentally, an enhanced interest in probiotic bacteria (those which confer health benefits) has developed recently among both the scientific community and lay public. The majority of studies addressing pathogenic or beneficial microbial influences on gastrointestinal illnesses have focused on irritable bowel and the inflammatory bowel diseases. More recently, several lines of evidence have emerged that link the presence and composition of the luminal microbiota to the intestinal response to radiation. These include relative radiation resistance of germ-free mice, altered intestinal responses to radiation associated with colonization by commensal and probiotic bacterial species and recognition that stimulation of, or alteration in, innate immune system pathways modifies host responses to radiation. Radiation enteropathy remains a common complication for patients receiving abdominal or pelvic radiotherapy for cancer. Prophylactic or therapeutic strategies against radiation enteropathy are currently limited. However, as in other intestinal disorders, recent studies aimed at elucidating functions of the hostmicrobiome relationship in radiation injury have provided insight into both disease pathophysiology and potential therapeutics. Our opinion will provide a background review on radiation-induced intestinal injury while examining in greater detail the data for microbial influences on this disease entity.

\section{Radiation enteropathy in clinical medicine}

Radiation therapy is used commonly for many forms of solid cancers including those that develop within the abdominal or pelvic cavities. A particular challenge that remains for the clinician is the lack of an available quantitative biomarker to measure the presence and degree of intestinal damage.

\section{Scope and impact}

More than $50 \%$ of patients with cancer receive radiation as a component of their treatment. The small intestine is rarely a primary target in radiotherapy, but by nature of its size and extent, it often receives exposure resulting in collateral damage. The rapidly proliferating mucosal lining of the small intestine is highly radiosensitive, and the resulting cell death leads to symptoms of malabsorption, including bloating, diarrhea and dehydration.

Abdominal pain, anorexia, nausea and vomiting can also occur and are amplified by concurrent chemotherapy [2,3]. Symptoms adversely affect patient quality of life and can be severe enough to require hospitalization. The damaging effects related to small intestinal injury are a major reason for dose limitation and can force discontinuation of radiotherapy, impacting overall chances for cure of malignancy.

Patients typically experience symptoms from acute small intestinal injury after the first or second week of radiotherapy [4]. The effect is dosage-dependent wherein low doses lead to mild and reversible disease and higher doses result in more severe and potentially irreversible damage. Thus, clinical regimens are usually designed to offer fractionated lowdosage ( $<2 \mathrm{~Gy}$ ) therapy in multiple sessions over the course of weeks. Extensive planning goes into treatment field design for radiation therapy to minimize the amount of small bowel 
which is exposed. Regardless, it is estimated that up to $70 \%$ or more of patients experience adverse gastrointestinal side effects by 3 weeks into therapy. Most of these acute symptoms subside by $2-6$ weeks following completion of radiation therapy. Chronic severe complications of radiation enteropathy include dysmotility, strictures and fistulas, and occur in approximately $6 \%$ of patients 1 to 2 years after radiation therapy [5]. Interestingly, both acute and chronic radiation therapy-related toxicities may be more severe in patients with preexisting conditions of intestinal compromise or microbial dysbiosis such as those occurring in patients with inflammatory bowel diseases [6,7].

\section{Diagnosis}

The diagnosis of acute radiation enteropathy is usually presumptively based on symptom type and time of onset. Basic laboratories, stool studies and abdominal imaging can be performed depending on symptom severity, but are often uninformative. Endoscopic biopsies are rarely used, although they may reveal histologic changes consistent with radiation damage. No specific biomarkers for radiation enteropathy are in common use; however, new potential serum or stool markers are being tested. Citrulline is a nitrogencontaining end product of small bowel enterocyte metabolism. Serum citrulline has been evaluated as a biomarker for functional enterocyte mass [8]. In radiation enteropathy, testing of the feasibility and functionality of this biomarker in mice and in humans has revealed that it shows promise as a novel diagnostic test [9-11]. Fecal calprotectin is another potential biomarker, which has been shown to significantly increase after pelvic radiation [11]. However, as a neutrophil-derived protein, calprotectin is not small bowel-specific. Eosinophilic cationic protein levels [12] and C-reactive protein levels [13] have also been found to be increased in patients following pelvic irradiation, although not consistently [11]. It is possible that in the future, sequential evaluation of a cluster of markers will prove most informative for diagnosis and monitoring.

\section{Pathophysiology of small bowel radiation injury}

Acute radiation injury to the small intestine has been well documented in animal models. When interpreting the literature, it is useful to recognize that whereas clinical medicine uses small fractionated doses of ionizing radiation, most animal studies evaluating mechanisms of disease use higher dose, single-exposure regimens, as would be encountered in accidental or warfare-associated ionizing radiation overexposure. Figure 1 ([14-18,19•, 20-24,25•,26•, 27]) summarizes several recent findings.

\section{Epithelial and endothelial responses}

Radiation-induced small intestinal injury is characterized by cell loss in the progenitor cell compartment [28] and a dose-dependent loss of barrier properties [29-31]. Ionizing radiation causes a wide diversity of functional disorders in the small intestine, including altered motility [32,33], disrupted absorption of carbohydrates [34], amino acids and bile acids [35], and a more thrombophilic endothelium due to the induction of inflammatory cell adhesion to the endothelium [36] and increased expression of endothelial von Willebrand factor [37]. 
It has traditionally been assumed that the radiation gastrointestinal syndrome that ensues with exposure to high doses of radiation or cumulative lower doses results from the direct killing of the rapidly proliferating epithelial stem cells, depletion of the differentiated parenchymal cells and subsequent loss of tissue function [38]. However, vascular damage also ensues when the small intestine is exposed to ionizing radiation [39]. A study [14] published in 2001 suggested that the radiation gastrointestinal syndrome is a direct consequence of an early (4-h) wave of apoptosis in the intestinal vascular endothelial cells. Recently, this assertion was challenged by Schuller et al. [15] who exposed two groups of mice to an equivalent dose of total body irradiation (TBI), then directly targeted intestinal endothelial cells in one of the groups of mice with up to 27-Gy neutron beam irradiation and found no additional intestinal crypt stem cell loss or murine death related to the gastrointestinal syndrome.

\section{Unanticipated overexposure to ionizing radiation}

In clinical medicine, small fractionated doses of radiation are used. In mice exposure to doses of $8 \mathrm{~Gy}$ or higher leads to sterilization of individual small intestinal crypts, a process in which all of the actual and potential stem cells are inactivated. The survival of one or more clonogenic cells in a given crypt allows the regeneration of that crypt. Doses of $15 \mathrm{~Gy}$ and higher sterilize virtually all of the crypt stem cells, resulting in complete loss of the intestinal villi and death from the radiation gastrointestinal syndrome in 4-5 days [15]. This syndrome is characterized by breaches in the intestinal mucosa, translocation of commensal intestinal bacteria and sepsis, and it is relevant in cases of bioterrorist attacks, nuclear accidents, medical errors and in appropriately fractionated dosing of therapeutic radiation to people whose tissues are exquisitely radiosensitive.

\section{Linking the microbiota to the intestinal response to radiation}

It had previously been observed that germ-free mice have improved survival as compared with colonized mice when exposed to equivalent doses of radiation [40]. However, the impact of the intestinal microbiota on the pathogenesis of the radiation gastrointestinal syndrome was not understood until a more recent work by Crawford and Gordon [16]. Here, hematopoietic rescue by bone marrow transplantation after lethal ionizing radiation was used to demonstrate that conventionally raised mice still exhibited earlier death than germfree mice [16]. Using Rag1 knockout mice, they also showed that mature lymphocytes are not required for the development of lethal radiation enteropathy. Mechanistically, the investigation also suggested that increased expression of a fibrinogen/angiopoietin-like protein, fasting-induced adipose factor, which is normally suppressed by luminal microbiota, confers endothelial and lymphocyte radioresistance.

Recognition of commensal intestinal bacteria or their products by Toll-like receptors (TLRs) is necessary for the regulation of intestinal homeostasis [41]. It is largely through binding to these receptors and the subsequent activation of the nuclear factor-kappa B $(\mathrm{NF}-\kappa \mathrm{B})$ family of transcription factors that commensal bacteria have been shown to influence the small intestinal epithelial response to various forms of injury. Recent animal models have revealed that this is true for radiation-induced injury. Egan et al. [17] showed increased intestinal epithelial cell (IEC) apoptosis in mice with selected ablation of $N F-\kappa B$ signaling through 
I $\kappa \mathrm{B}$ kinase, a common activation pathway for TLR signaling. This finding corresponded with increased expression and activation of the tumor suppressor p53. Mice in which the $N F-k B$ p 50 gene has been disrupted were shown to be more sensitive to TBI-induced lethality than are wild-type mice [18]. These findings demonstrate the physiological importance of NF- $\kappa \mathrm{B}$ activation in protection against radiation-induced death in the epithelium in vivo, and directly link intestinal commensal bacteria to the regulation of radiation-induced IEC apoptosis. Recent mouse knockout studies have revealed that bacterial products also activate signaling pathways other than the NF- $\kappa B$ pathway to protect IECs from radiation-induced apoptosis [19•].

Both endogenous and exogenous sources of prostaglandins have been shown to confer protection to intestinal crypts that are exposed to radiation. In mice, parenterally administered lipopolysaccharide, a TLR4 ligand, increased endogenous intestinal prostaglandin production, thereby improving intestinal crypt survival after irradiation [20]. Exogenous administration of a prostaglandin $\mathrm{E}_{2}\left(\mathrm{PGE}_{2}\right)$ analogue prior to radiation also increases the number of surviving intestinal crypts. Several studies have demonstrated that the radioprotective effect of prostaglandins on the gut is a cyclooxygenase (COX)-1dependent, COX-2-independent event. Irradiated $\mathrm{COX}-1^{-/-}$mice have increased crypt epithelial apoptosis, decreased clonogenic stem cell survival and diminished $\mathrm{PGE}_{2}$ synthesis as compared with wild-type littermates [21]. Administration of indomethacin, which inhibits both COX-1 and COX-2, to a mouse prior to radiation increases radiation-induced IEC apoptosis and decreases intestinal crypt survival [22]. However, selective COX-2 inhibitors have no effect on crypt survival; likewise $\mathrm{COX}-2^{-/-}$mice have a similar response to radiation to wild-type mice. So, the COX-1-dependent production of endogenous $\mathrm{PGE}_{2}$ appears to be an important downstream mediator of TLR signaling by which bacterial products promote IEC survival and proliferation in the response to radiation [23]. The biologic effects of $\mathrm{PGE}_{2}$ have been shown to be mediated via AKT activation by the plasma membrane G-protein-coupled receptor EP2 [24], thereby preventing Bax translocation to the mitochondria [42].

\section{Human polymorphisms and variations in microbiome}

There are emerging, although not yet matured, data supporting the role of host and microbial genetic influences on the radiosensitivity of the small intestine. A recent study [43] identified a correlation between single-nucleotide polymorphisms in mice and the amount of jejunal crypt cell apoptosis after 2.5-Gy TBI. Gene expression microarrays have also been used in attempts to predict the radiosensitivity of normal tissue [44].

An intriguing recent study [45•] involving a small number of patients used DNA fingerprinting with $16 \mathrm{~S}$ ribosomal RNA denaturing gradient gel electrophoresis (DGGE) to show different fecal microbial profiles in people receiving radiation who experienced diarrhea from those who received radiation and maintained normal stool consistency. They evaluated stool before, during and after radiation, and proposed that a dysbiosis was linked to changes in bowel habits rather than the radiation exposure itself. Interestingly, the microbial profiles of individuals before receiving radiation clustered in three similarity sets that matched closely the control, the 'no diarrhea' and the 'diarrhea' groups, suggesting that 
the initial intestinal microbial composition of each individual could be a determinant for developing postirradiation diarrhea.

\section{Current management principles}

In cancer therapy, use of well planned [46,47], fractionated dose regimens with specific patient positioning remains key to minimizing symptoms of radiation enteropathy. Additionally, numerous pharmacologic therapies have been tested for reducing symptoms. Antispasmodic and antidiarrheal agents are effective for some patients. Cholestyramine has been shown to be effective in reducing bile salt-associated diarrhea, which can occur with radiation enteropathy [48]. Amifostine, a broad-spectrum, free-radical scavenging cytoprotectant, is used as an adjuvant with treatment of some malignancies [49]. Although the benefits of this drug are clear for xerostomia, its ability to prevent radiation enteropathy has not been proven and the side effect of hypotension has tempered interest in routine use.

Most current therapies for radiation enteropathy are initiated only after symptoms develop. As the percentage of patients who develop small bowel symptoms is high, widespread use of an effective prophylactic agent would likely be adopted if it became available. An ideal prophylactic radioprotectant for the small intestine would need to fulfill specific requirements including the possession of an ability to preserve or enhance the antitumor efficacy of radiation; the provision of wide-ranged normal tissue protection with a lowtoxicity profile and the allowance of easy, safe and cost-effective administration.

\section{Microbial manipulation in therapy or prevention}

Development of small intestinal radioprotectants has primarily focused on antioxidants [5054], modifiers of inflammation [55-57], growth factors [58-60] and regulators of IEC apoptosis $[61,62]$. Yet, recent evidence suggests that manipulation of the intestinal luminal microbiota or the administration of medications adapted from commensal or probiotic bacteria holds promise in providing prophylactic and possibly postexposure enteric radioprotection.

\section{Bacterial product-based therapies}

Burdelya et al. $[25 \bullet \bullet, 63]$ recently evaluated a polypeptide drug derived from Salmonella flagellin that binds to TLR5 and activates NF- $\kappa \mathrm{B}$ signaling. A single injection of this agent improved survival in mice exposed to radiation by limiting apoptosis and preserving cell proliferation in the epithelial crypts and lamina propria of the small intestine. However, protection was conferred only when mice were exposed to doses below those that universally cause the radiation gastrointestinal syndrome, and only if the agent was administered 15-60 min before exposure. In similar experiments using rhesus macaques, the investigators observed that the TLR5 agonist increased survival and had protective effects on bone marrow, although they did not provide data on the effect of the agonist on the gastrointestinal tract of the monkeys. Remarkably, this drug did not appear to decrease tumor radiosensitivity in the mouse model used. Hence, this TLR5 agonist is potentially useful as a prophylactic before therapeutic radiation, but may not be adequate as a treatment for the radiation gastrointestinal syndrome, as in the case of a nuclear accident or attack. 
Probiotics are live microbial organisms, most often bacteria, which confer beneficial effects to the host when consumed. With increasing evidence suggesting that imbalance of the intestinal microbiota may play a significant role in the pathogenesis of radiation enteropathy, probiotic bacteria are now attracting interest as potential radioprotectants. Single and multistrain probiotic preparations have been evaluated in both animal models and humans over the last few decades. In rodents, Lactobacillus species have been shown to reduce radiation-induced small intestinal damage, Gram-negative bacteremia, endotoxemia and death $[26 \bullet, 64,65]$. Primary endpoints were not achieved for probiotics in small trials in which humans underwent pelvic radiation for cancer; however, individuals receiving Lactobacillus supplementation showed a trend toward having less severe symptoms $[27,66,67]$. In the largest human trial [68] to date, patients taking the probiotic mixture VSL\#3 experienced radiation-induced diarrhea less frequently than patients taking a placebo in a double-blind study involving almost 500 patients. Timing of probiotic administration, prophylactic versus therapeutic, respectively, may explain the more robust results identified in animal studies as compared with human trials. Early reports also suggest that soluble secreted factors from probiotic bacteria may be responsible for physiologic benefits observed in radiation [26•] as in other injury models [69]. As probiotic bacteria are inexpensive and would be predicted to offer extensive tissue protection with low toxicity, further investigation into their role as intestinal radioprotectants is warranted.

\section{Antibiotics}

Antibiotics have been considered for decades as a potential treatment option for radiation enteropathy [70]. Researchers at the Armed Forces Radiobiology Research Institute used antibiotics in several radiation mouse models [71-73]. Limitations to these studies included their focus on the activity of various antibiotics specifically against orally ingested pathogens, their use of bacterial translocation to the liver and mortality as primary readouts, and their evaluation of radiation doses that were not sufficient to cause the radiation gastrointestinal syndrome. In their most recent review, this group summarized their findings and concluded that the potential use of several different antimicrobial agents from various classes may be effective for treating infection after exposure to radiation, but they do not identify a superior agent [74].

Intestinal commensal bacteria translocate across the intestinal mucosa and cause sepsis and early death in response to high doses of radiation. Yet, the aforementioned studies linking TLR binding by bacterial products to protection of the intestinal epithelium and the host against radiation-induced damage suggest that some commensal intestinal bacterial species provide protective functions in the response to radiation. Hence, an antibiotic that uniquely targets bacterial organisms that tend to translocate after exposure to radiation, while sparing bacterial species that are shown to be protective in the response of the intestinal epithelium and the host to radiation, may be optimal. This concept also lends support to the prophylactic and/or therapeutic potential of administrating both an antibiotic and a probiotic to people exposed to radiation. 


\section{Conclusion}

Radiation injury to the small bowel remains an important clinical problem for which few therapeutic strategies exist. Several lines of evidence, which were reviewed here, suggest that dynamic interactions between the host's enteric microbiota and innate immune system modulate the intestinal response to radiation. Probiotics, antibiotics and bacterial-derived peptides and byproducts can modify radiation-induced injury and symptom severity. How to best harness the influence of these microbial symbionts remains to be determined. Future laboratory studies should be aimed at identifying specific prebiotic, probiotic, antibiotic or all regimens that optimize normal tissue radioresistance and tumoral radiosensitization. Bacterial-based compounds or secreted products will likely be an area of fruitful investigation. Clinical studies in this area should initially focus on clarifying how intestinal microbial compositions shift in response to radiation. Using this knowledge, strain-specific probiotics could be administered to increase bacterial species that best confer host radioprotection. Likewise, antibiotic regimens could be developed that selectively target bacterial species that are found to proliferate, translocate and cause sepsis following exposure to radiation, while possessing minimal activity against the protective bacterial populations. Subsequent clinical studies should be aimed at determining the safety, efficacy and applicability of the developing therapeutic agents and regimens. Recent years have seen an explosive growth in knowledge associating the microbiome to human health; the prevention or treatment of small intestinal radiation injury should serve as a particularly productive target for future investigations in this area.

\section{Acknowledgments}

M.A.C. holds a Career Development Award from the Crohn's and Colitis Foundation of America and is the recipient of Global Probiotics Council's Young Investigator Grant. C.D.P. is supported by a National Institutes of Health T-32 DK07737 training grant. The authors thank Dr Scott Magness for assistance in development of Fig. 1.

\section{References and recommended reading}

Papers of particular interest, published within the annual period of review, have been highlighted as:

- of special interest

- of outstanding interest

Additional references related to this topic can also be found in the Current World Literature section in this issue (p. 170).

1 •. Peterson J. The NIH Human Microbiome Project. Genome Res. 2009; 19:2317-2323. [PubMed: 19819907] This is a description of the history and implementation of the HMP, a 5-year, U.S. $\$ 150$ million initiative with the aim of utilizing high-throughput technologies to characterize the human microbiome from multiple body sites from at least 250 'normal' volunteers. The ultimate objective of the HMP is to demonstrate that human health can be improved through monitoring or manipulating the human microbiome.

2. Gunnlaugsson A, Kjellen E, Nilsson P, et al. Dose-volume relationships between enteritis and irradiated bowel volumes during 5-fluorouracil and oxaliplatin based chemoradiotherapy in locally advanced rectal cancer. Acta Oncol. 2007; 46:937-944. [PubMed: 17851844] 
3. Tho LM, Glegg M, Paterson J, et al. Acute small bowel toxicity and pre-operative chemoradiotherapy for rectal cancer: investigating dose-volume relationships and role for inverse planning. Int J Radiat Oncol Biol Phys. 2006; 66:505-513. [PubMed: 16879928]

4. Bismar MM, Sinicrope FA. Radiation enteritis. Curr Gastroenterol Rep. 2002; 4:361-365. [PubMed: 12228037]

5. Sher ME, Bauer J. Radiation-induced enteropathy. Am J Gastroenterol. 1990; 85:121-128. [PubMed: 2301333]

6. Song DY, Lawrie WT, Abrams RA, et al. Acute and late radiotherapy toxicity in patients with inflammatory bowel disease. Int J Radiat Oncol Biol Phys. 2001; 51:455-459. [PubMed: 11567821]

7. Willett CG, Ooi CJ, Zietman AL, et al. Acute and late toxicity of patients with inflammatory bowel disease undergoing irradiation for abdominal and pelvic neoplasms. Int J Radiat Oncol Biol Phys. 2000; 46:995-998. [PubMed: 10705022]

8. Lutgens L, Lambin P. Biomarkers for radiation-induced small bowel epithelial damage: an emerging role for plasma citrulline. World J Gastroenterol. 2007; 13:3033-3042. [PubMed: 17589917]

9. Lutgens LC, Deutz N, Granzier-Peeters M, et al. Plasma citrulline concentration: a surrogate end point for radiation-induced mucosal atrophy of the small bowel. A feasibility study in 23 patients. Int J Radiat Oncol Biol Phys. 2004; 60:275-285. [PubMed: 15337566]

10. Lutgens LC, Deutz NE, Gueulette J, et al. Citrulline: a physiologic marker enabling quantitation and monitoring of epithelial radiation-induced small bowel damage. Int J Radiat Oncol Biol Phys. 2003; 57:1067-1074. [PubMed: 14575838]

11. Wedlake L, McGough C, Hackett C, et al. Can biological markers act as noninvasive, sensitive indicators of radiation-induced effects in the gastrointestinal mucosa? Aliment Pharmacol Ther. 2008; 27:980-987. [PubMed: 18315578]

12. Bowen JM, Newbold K, Blake P, et al. Do serum levels of eosinophil granule-derived protein change in patients undergoing pelvic radiotherapy? Clin Oncol (R Coll Radiol). 2005; 17:382-384. [PubMed: 16097571]

13. Cengiz M, Akbulut S, Atahan IL, Grigsby PW. Acute phase response during radiotherapy. Int J Radiat Oncol Biol Phys. 2001; 49:1093-1096. [PubMed: 11240251]

14. Paris F, Fuks Z, Kang A, et al. Endothelial apoptosis as the primary lesion initiating intestinal radiation damage in mice. Science. 2001; 293:293-297. [PubMed: 11452123]

15. Schuller BW, Binns PJ, Riley KJ, et al. Selective irradiation of the vascular endothelium has no effect on the survival of murine intestinal crypt stem cells. Proc Natl Acad Sci U S A. 2006; 103:3787-3792. [PubMed: 16505359]

16. Crawford PA, Gordon JI. Microbial regulation of intestinal radiosensitivity. Proc Natl Acad Sci U S A. 2005; 102:13254-13259. [PubMed: 16129828]

17. Egan LJ, Eckmann L, Greten FR, et al. IkappaB-kinasebeta-dependent NF-kappaB activation provides radioprotection to the intestinal epithelium. Proc Natl Acad Sci U S A. 2004; 101:24522457. [PubMed: 14983030]

18. Wang Y, Meng A, Lang H, et al. Activation of nuclear factor kappaB in vivo selectively protects the murine small intestine against ionizing radiation-induced damage. Cancer Res. 2004; 64:62406246. [PubMed: 15342410]

19 • Garin-Laflam MP, Steinbrecher KA, Rudolph JA, et al. Activation of guanylate cyclase C signaling pathway protects intestinal epithelial cells from acute radiation-induced apoptosis. Am J Physiol Gastrointest Liver Physiology. 2009; 296:G740-G749. The heat-stable enterotoxin of Escherichia coli is a ligand for guanylate cyclase C (GC-C), an IEC transmembrane receptor. Using an alternative ligand, uroguanylin, in GC-C knockout mice, it is shown that this pathway is important in mediating intestinal radioprotection.

20. Riehl T, Cohn S, Tessner T, et al. Lipopolysaccharide is radioprotective in the mouse intestine through a prostaglandin-mediated mechanism. Gastroenterology. 2000; 118:1106-1116. [PubMed: 10833485]

21. Houchen CW, Stenson WF, Cohn SM. Disruption of cyclooxygenase-1 gene results in an impaired response to radiation injury. Am J Physiol Gastrointest Liver Physiol. 2000; 279:G858-G865. [PubMed: 11052981] 
22. Cohn SM, Schloemann S, Tessner T, et al. Crypt stem cell survival in the mouse intestinal epithelium is regulated by prostaglandins synthesized through cyclooxygenase-1. J Clin Invest. 1997; 99:1367-1379. [PubMed: 9077547]

23. Stenson WF. Prostaglandins and epithelial response to injury. Curr Opin Gastroenterology. 2007; 23:107-110.

24. Houchen CW, Sturmoski MA, Anant S, et al. Prosurvival and antiapoptotic effects of PGE2 in radiation injury are mediated by EP2 receptor in intestine. Am J Physiol Gastrointest Liver Physiology. 2003; 284:G490-G498.

$25 \bullet$. Burdelya LG, Krivokrysenko VI, Tallant TC, et al. An agonist of toll-like receptor 5 has radioprotective activity in mouse and primate models. Science. 2008; 320:226-230. [PubMed: 18403709] This study reported an enhanced intestinal crypt cell proliferative response and decreased mortality in mice and nonhuman primates exposed to lethal doses of radiation following just one injection of a polypeptide derivative of flagellin, a TLR5 ligand.

$26 \bullet$ Ciorba MA, Stenson WF. Probiotic therapy in radiation-induced intestinal injury and repair. Ann N Y Acad Sci. 2009; 1165:190-194. [PubMed: 19538306] This review summarizes the results of human studies and animal models largely published from 2000 to 2008 that investigated the use of probiotics to treat radiation enteropathy. Newer data suggest that particular probiotics, their secreted or derived bacterial products or both may have unique radioprotective properties.

27. Osterlund P, Ruotsalainen T, Korpela R, et al. Lactobacillus supplementation for diarrhoea related to chemotherapy of colorectal cancer: a randomised study. Br J Cancer. 2007; 97:1028-1034. [PubMed: 17895895]

28. Potten CS. A comprehensive study of the radiobiological response of the murine (BDF1) small intestine. Int J Radiat Biol. 1990; 58:925-973. [PubMed: 1978853]

29. Dublineau I, Grison S, Grandcolas L, et al. Effects of chronic 137Cs ingestion on barrier properties of jejunal epithelium in rats. J Toxicol Environ Health A. 2007; 70:810-819. [PubMed: 17454557]

30. Guzman-Stein G, Bonsack M, Liberty J, Delaney JP. Abdominal radiation causes bacterial translocation. J Surg Res. 1989; 46:104-107. [PubMed: 2918713]

31. Molla M, Gironella M, Miquel R, et al. Relative roles of ICAM-1 and VCAM-1 in the pathogenesis of experimental radiation-induced intestinal inflammation. Int J Radiat Oncol Biol Phys. 2003; 57:264-273. [PubMed: 12909242]

32. Otterson MF. Effects of radiation upon gastrointestinal motility. World J Gastroenterol. 2007; 13:2684-2692. [PubMed: 17569136]

33. Picard C, Wysocki J, Fioramonti J, Griffiths NM. Intestinal and colonic motor alterations associated with irradiation-induced diarrhoea in rats. Neurogastroenterol Motil. 2001; 13:19-26. [PubMed: 11169122]

34. Overgaard J, Matsui M. Effect of radiation on glucose absorption in the mouse jejunum in vivo. Radiother Oncol. 1990; 18:71-77. [PubMed: 2359850]

35. Thomson AB, Cheeseman CI, Walker K. Intestinal uptake of bile acids: effect of external abdominal irradiation. Int J Radiat Oncol Biol Phys. 1984; 10:671-685. [PubMed: 6735756]

36. Dunn MM, Drab EA, Rubin DB. Effects of irradiation on endothelial cell-polymorphonuclear leukocyte interactions. J Appl Physiol. 1986; 60:1932-1937. [PubMed: 3522532]

37. van Kleef E, Verheij M, te Poele H, et al. In vitro and in vivo expression of endothelial von Willebrand factor and leukocyte accumulation after fractionated irradiation. Radiat Res. 2000; 154:375-381. [PubMed: 11023600]

38. Potten CS. Radiation, the ideal cytotoxic agent for studying the cell biology of tissues such as the small intestine. Radiat Res. 2004; 161:123-136. [PubMed: 14731078]

39. Wang J, Boerma M, Fu Q, Hauer-Jensen M. Significance of endothelial dysfunction in the pathogenesis of early and delayed radiation enteropathy. World J Gastroenterol. 2007; 13:30473055. [PubMed: 17589919]

40. McLaughlin MM, Dacquisto MP, Jacobus DP, Horowitz RE. Effects of the germfree state on responses of mice to whole-body irradiation. Radiat Res. 1964; 23:333-349. [PubMed: 14229117]

41. Rakoff-Nahoum S, Paglino J, Eslami-Varzaneh F, et al. Recognition of commensal microflora by toll-like receptors is required for intestinal homeostasis. Cell. 2004; 118:229-241. [PubMed: 15260992] 
42. Tessner TG, Muhale F, Riehl TE, et al. Prostaglandin E2 reduces radiation-induced epithelial apoptosis through a mechanism involving AKT activation and bax translocation. J Clin Invest. 2004; 114:1676-1685. [PubMed: 15578100]

43. Iwata M, Iwakawa M, Noda S, et al. Correlation between single nucleotide polymorphisms and jejunal crypt cell apoptosis after whole body irradiation. Int J Radiat Biol. 2007; 83:181-186. [PubMed: 17378526]

44. Kruse JJ, Stewart FA. Gene expression arrays as a tool to unravel mechanisms of normal tissue radiation injury and prediction of response. World J Gastroenterol. 2007; 13:2669-2674. [PubMed: 17569134]

45 - Manichanh C, Varela E, Martinez C, et al. The gut microbiota predispose to the pathophysiology of acute postradiotherapy diarrhea. Am J Gastroenterol. 2008; 103:1754-1761. [PubMed: 18564125] This study is noteworthy because it is one of the first studies to utilize molecular techniques, in this case DGGE, to survey the intestinal microbiota after exposure to radiation. This was conducted in 10 human patients before, during and after therapeutic radiation for malignancies, and revealed clustering of patient groups that correlated with the nature of postirradiation bowel habits and not with exposure to radiation in and of itself.

46. Engels B, De Ridder M, Tournel K, et al. Preoperative helical tomotherapy and megavoltage computed tomography for rectal cancer: impact on the irradiated volume of small bowel. Int $\mathrm{J}$ Radiat Oncol Biol Phys. 2009; 74:1476-1480. [PubMed: 19231097]

47. Fiorino C, Valdagni R, Rancati T, Sanguineti G. Dose-volume effects for normal tissues in external radiotherapy: pelvis. Radiother Oncol. 2009; 93:153-167. [PubMed: 19765845]

48. Heusinkveld RS, Manning MR, Aristizabal SA. Control of radiation-induced diarrhea with cholestyramine. Int J Radiat Oncol Biol Phys. 1978; 4:687-690. [PubMed: 101491]

49. Weiss JF, Landauer MR. History and development of radiation-protective agents. Int J Radiat Biol. 2009; 85:539-573. [PubMed: 19557599]

50. Guo HL, Wolfe D, Epperly MW, et al. Gene transfer of human manganese superoxide dismutase protects small intestinal villi from radiation injury. J Gastrointest Surg. 2003; 7:229-235. discussion 235-236. [PubMed: 12600447]

51. Haton C, Francois A, Vandamme M, et al. Imbalance of the antioxidant network of mouse small intestinal mucosa after radiation exposure. Radiat Res. 2007; 167:445-453. [PubMed: 17388695]

52. Huang EY, Wang FS, Lin IH, Yang KD. Aminoguanidine alleviates radiation-induced small-bowel damage through its antioxidant effect. Int J Radiat Oncol Biol Phys. 2009; 74:237-244. [PubMed: 19362242]

53. Hussein MR, Abu-Dief EE, Kamel E, et al. Melatonin and roentgen irradiation-induced acute radiation enteritis in albino rats: an animal model. Cell Biol Int. 2008; 32:1353-1361. [PubMed: 18762261]

54. Abbasoglu SD, Erbil Y, Eren T, et al. The effect of heme oxygenase-1 induction by octreotide on radiation enteritis. Peptides. 2006; 27:1570-1576. [PubMed: 16375990]

55. Boerma M, Wang J, Burnett AF, et al. Local administration of interleukin-11 ameliorates intestinalradiationinjury in rats. Cancer Res. 2007; 67:9501-9506. [PubMed: 17909060]

56. Boerma M, Wang J, Richter KK, Hauer-Jensen M. Orazipone, a locally acting immunomodulator, ameliorates intestinal radiation injury: a preclinical study in a novel rat model. Int J Radiat Oncol Biol Phys. 2006; 66:552-559. [PubMed: 16965997]

57. Kawashima R, Kawamura YI, Kato R, et al. IL-13 receptor alpha2 promotes epithelial cell regeneration from radiation-induced small intestinal injury in mice. Gastroenterology. 2006; 131:130-141. [PubMed: 16831597]

58. Hagiwara A, Nakayama F, Motomura K, et al. Comparison of expression profiles of several fibroblast growth factor receptors in the mouse jejunum: suggestive evidence for a differential radioprotective effect among major FGF family members and the potency of FGF1. Radiat Res. 2009; 172:58-65. [PubMed: 19580507]

59. Lee KK, Jo HJ, Hong JP, et al. Recombinant human epidermal growth factor accelerates recovery of mouse small intestinal mucosa after radiation damage. Int J Radiat Oncol Biol Phys. 2008; 71:1230-1235. [PubMed: 18572086] 
60. Potten CS, Booth D, Haley JD. Pretreatment with transforming growth factor beta-3 protects small intestinal stem cells against radiation damage in vivo. Br J Cancer. 1997; 75:1454-1459.

[PubMed: 9166937]

61. Haegebarth A, Perekatt AO, Bie W, et al. Induction of protein tyrosine kinase 6 in mouse intestinal crypt epithelial cells promotes DNA damage-induced apoptosis. Gastroenterology. 2009; 137:945954. [PubMed: 19501589]

62. Qiu W, Carson-Walter EB, Liu H, et al. PUMA regulates intestinal progenitor cell radiosensitivity and gastrointestinal syndrome. Cell Stem Cell. 2008; 2:576-583. [PubMed: 18522850]

63. Abreu MT. Harnessing the power of bacteria to protect the gut. N Engl J Med. 2008; 359:756-759. [PubMed: 18703481]

64. Demirer S, Aydintug S, Aslim B, et al. Effects of probiotics on radiation-induced intestinal injury in rats. Nutrition. 2006; 22:179-186. [PubMed: 16459231]

65. Seal M, Naito Y, Barreto R, et al. Experimental radiotherapy-induced enteritis: a probiotic interventional study. J Dig Dis. 2007; 8:143-147. [PubMed: 17650226]

66. Giralt J, Regadera JP, Verges R, et al. Effects of probiotic Lactobacillus casei DN-114 001 in prevention of radiation-induced diarrhea: results from multi-center, randomized, placebocontrolled nutritional trial. Int J Radiat Oncol Biol Phys. 2008; 71:1213-1219. [PubMed: 18243569]

67. Urbancsek H, Kazar T, Mezes I, Neumann K. Results of a double-blind, randomized study to evaluate the efficacy and safety of antibiophilus in patients with radiation-induced diarrhoea. Eur $\mathbf{J}$ Gastroenterol Hepatol. 2001; 13:391-396. [PubMed: 11338068]

68. Delia P, Sansotta G, Donato V, et al. Use of probiotics for prevention of radiation-induced diarrhea. World J Gastroenterol. 2007; 13:912-915. [PubMed: 17352022]

69. Yan F, Cao H, Cover TL, et al. Soluble proteins produced by probiotic bacteria regulate intestinal epithelial cell survival and growth. Gastroenterology. 2007; 132:562-575. [PubMed: 17258729]

70. Livstone EHT, Spiro H, Floch M. The gastrointestinal microflora of irradiated mice. II. Effect of oral antibiotic administration on the colonic flora and survival of adult mice. Yale J Biol Med. 1970; 42:448-454. [PubMed: 5431866]

71. Brook I, Elliott TB, Ledney GD. Quinolone therapy of Klebsiella pneumoniae sepsis following irradiation: comparison of pefloxacin, ciprofloxacin, and ofloxacin. Radiat Res. 1990; 122:215217. [PubMed: 2186431]

72. Brook I, Tom SP, Ledney GD. Development of infection with Streptococcus bovis and Aspergillus sp. in irradiated mice after glycopeptide therapy. J Antimicrob Chemother. 1993; 32:705-713. [PubMed: 8125835]

73. Brook I, Ledney GD. The treatment of irradiated mice with polymicrobial infection caused by Bacteroides fragilis and Escherichia coli. J Antimicrob Chemother. 1994; 33:243-252. [PubMed: 8182005]

74. Brook I, Elliott TB, Ledney GD, et al. Management of postirradiation infection: lessons learned from animal models. Mil Med. 2004; 169:194-197. [PubMed: 15080238] 


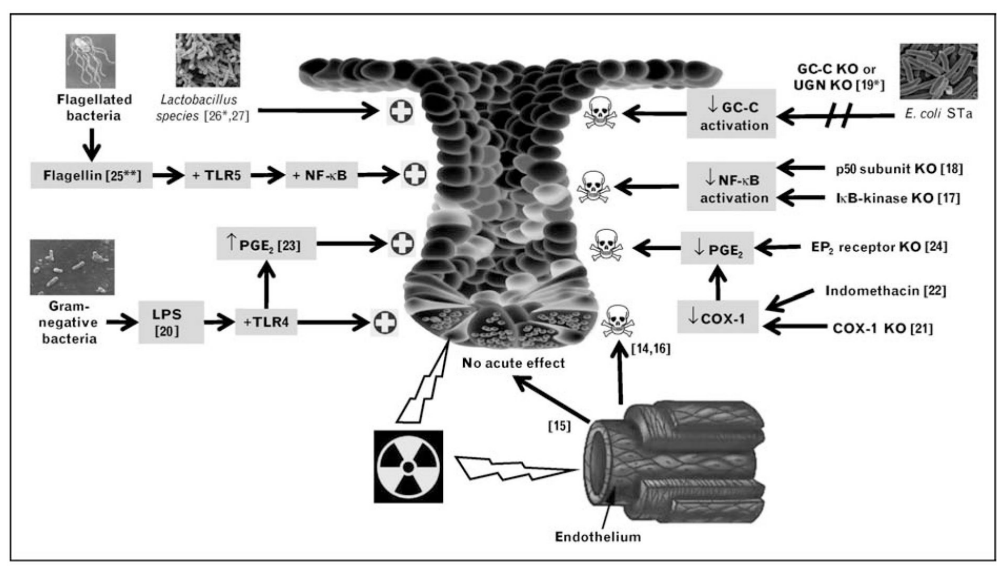

Figure 1. Modifiers of acute small intestinal radiation injury

The small intestinal response to radiation is altered by signaling induced by luminal bacteria or bacterial-based products. Experimental models and human trials suggest Lactobacillus species or their soluble secreted proteins alone may protect intestinal crypts against damage from radiation exposure $[26 \bullet, 27]$. Flagellin, a TLR5 ligand that activates the NF- $\kappa \mathrm{B}$ pathway, protected IECs from radiation-induced apoptosis and increased host survival when injected into mice before lethal doses of radiation [25••]. LPS, a TLR4 ligand that is found in the outer membrane of Gram-negative bacteria, increased both endogenous intestinal prostaglandin production and intestinal crypt survival in mice exposed to 14-Gy radiation when injected parenterally 2-24 h prior to exposure [20]. Endogenous PGE $_{2}$ has been shown to decrease murine IEC apoptosis and increase IEC proliferation in response to radiation [23]. Conversely, blocking pathways that are activated by bacterial products have been shown to have detrimental effects on the ability of IECs and crypts to survive radiation insults. The E. coli STa is a ligand for GC-C, an IEC transmembrane receptor. UGN is a peptide hormone that binds to and activates GC-C. Mice in which GC-C or UGN is knocked out have increased jejunal IEC apoptosis $3 \mathrm{~h}$ after 5-Gy radiation as compared with wildtype counterparts [19•]. Indomethacin blocks $\mathrm{PGE}_{2}$ production by inhibiting $\mathrm{COX}-1$ and COX-2, thereby increasing IEC apoptosis and intestinal crypt ablation [22]. Similarly, irradiated $\mathrm{COX}-1^{-/-}$mice have diminished $\mathrm{PGE}_{2}$ synthesis, leading to increased crypt epithelial apoptosis and decreased clonogenic stem cell survival [21]. Irradiated $\mathrm{EP}_{2}$ receptor $^{-/-}$mice also have decreased intestinal crypt survival and a 1.6-fold increase in IEC apoptosis [24]. Blocking NF- $\kappa \mathrm{B}$ activation by deleting the $\mathrm{p} 50$ subunit of the $\mathrm{NF}-\kappa \mathrm{B}$ complex [18] or the canonical NF- $\kappa \mathrm{B}$ activation kinase [17] results in increased radiationinduced IEC apoptosis in mice. Although debate still exists as to the degree of importance of endothelial apoptosis in acute intestinal outcomes after high-dose radiation exposure $[14,15]$, endothelial apoptosis is shown to be lower in germ-free than conventionally raised mice [16]. COX, cyclooxygenase; E. coli STa, heat-stable enterotoxin of Escherichia coli; GC-C, guanylate cyclase C; IEC, intestinal epithelial cell; KO, knocked out; LPS, lipopolysaccharide; NF- $\kappa \mathrm{B}$, nuclear factor-kappa B; $\mathrm{PGE}_{2}$, prostaglandin $\mathrm{E}_{2}$; TLR, Toll-like receptor; UGN, uroguanylin. (๑) Limits acute intestinal injury from radiation, (용 contributes to acute intestinal injury from radiation. 